\title{
Smart system for maintaining aquascape environment using internet of things based light and temperature controller
}

\author{
Daniel Patricko Hutabarat ${ }^{1}$, Rudy Susanto ${ }^{1}$, Bryan Prasetya ${ }^{1}$, Barry Linando ${ }^{1}$, \\ Senanayake Mudiyanselage Namal Arosha ${ }^{2}$ \\ ${ }^{1}$ Computer Engineering Department, Faculty of Engineering, Bina Nusantara University, Jakarta, Indonesia \\ ${ }^{2}$ Faculty of Science, University of Brunei, Gadong, Brunei
}

\begin{tabular}{l}
\hline \hline Article Info \\
\hline Article history: \\
Received Mar 17, 2021 \\
Revised Jun 9, 2021 \\
Accepted Jul 1, 2021 \\
\hline
\end{tabular}

Keywords:

ESP32

IoT application

Sensors

Smart system

\begin{abstract}
The purpose of this research is to create a smart system based on internet of things (IoT) application for a plant aquarium. This smart system helps users to maintain the environment's parameters of the plant aquarium. In this study, the parameters to be controlled by the system are light intensity and temperature. The hardware used to develop this system is the ESP32 as the microcontroller, BH1750FVI as the light sensor, high power led (HPL) lightemitting diodes (LED) lamp as the light source, DS18B20 as temperature sensor, the heater, and the $220 \mathrm{VAC}$ fan that is used to raise and lower the temperature. In this study also developed an application that is used by the user to provide input to the system. The developed application is then installed on the user's smartphone and used to connect the user to the system via the internet. The ease of adding and removing devices used on the system is a capability that is also being developed in this smart system. The developed system can produce light intensity with accuracy rate of $96 \%$ and always manage to keep the temperature within the predetermined range.
\end{abstract}

This is an open access article under the CC BY-SA license.

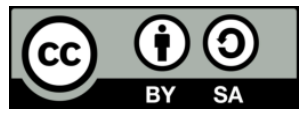

\section{Corresponding Author:}

Daniel Patricko Hutabarat

Computer Engineering Department, Bina Nusantara University

K. H. Syahdan 9 street, Palmerah, 11480, West Jakarta, Indonesia

Email: dhutabarat@binus.edu

\section{INTRODUCTION}

Aquascape is a manipulation of the aquatic ecosystem that is applied to an aquarium. In an aquascape environment, the subject of its beauty is aquatic plants, not fish or other aquatic animals, that is why we call it an aquarium plant. Aquarium plant is usually placed in the house so that the house becomes more beautiful, and the atmosphere becomes relaxed. Unlike the aquarium in general, aquascape emphasizes the growth of aquatic plants. Maintenance of aquatic plants in an aquascape is not much different from maintaining aquatic plants in other environments. Plants will grow well when the factors for photosynthesis are met. Because the function of this aquarium plant is to decorate the house and provide a relaxed atmosphere, this aquarium plant is usually placed in a room that lacks sunlight. This causes plants not to grow properly due to lack of light for photosynthesis. Plant needs for light vary depending on the plant category. Easy plants require light intensity 10-20 lumens per liter, medium plants require 20-40 lumens per liter, while Advance plants require 40 lumens per liter [1]. Additionally, aquatic plants tend to be more sensitive to temperature changes. Aquatic plants have different temperature ranges to grow well, but in general, aquatic plants grow well in the range of $25-28{ }^{\circ} \mathrm{C}$ and require at least 12 hours of lighting [2]. Light intensity and temperature are two important factors that must be monitored so that plants develop properly. However, currently these two factors are not properly monitored, causing damage to aquatic plants. 
The application of IoT currently covers almost all aspects of human life. The application of internet of things (IoT) in agriculture enables weeding, spraying, temperature and humidity monitoring to be carried out automatically, accurately and in real-time [3]. The same thing can also be applied to greenhouses where with IoT based application, checking or controlling in many greenhouses can be done centrally [4]. In addition, in the smart house, IoT based application allows users to get comfort, better efficiency in the use of electrical energy, to better security [5]. In IoT based application, microcontrollers are used to monitor and control the devices [6]-[11], whereas communication technologies such as Wi-Fi, internet, 4G and global system for mobile communications (GSM) are used to allow connections between devices with microcontroller and server [12]-[18]. Cloud technology is generally used to upload data from a device or smartphone to the server and download the required data from the server to the device or to a smartphone [19]-[23] while smartphone is used for system setup and monitoring [24]-[28].

In this research, an IoT application based system was designed for a smart aquarium plant using a controllable LED and a temperature controller. This system developed functions to maintain the parameters in the aquascape, especially the level of light intensity and water temperature. With this tool, it is expected that plants can grow well in accordance with the light level and water temperature required by the plants in the aquarium plant.

\section{RESEARCH METHOD}

Software and hardware are developed in this research and used to construct the system. The block diagram of the system is shown in the Figures 1 and 2. Based on the block diagram in Figure 1, the mobile application and ESP32 DevKit v1 are connected to each other via Cloud using the internet network. The $5 \mathrm{~V}$ power supply functions to provide voltage for the ESP32 DevKit v1 where the ESP32 will control the 24 Watt high power led (HPL) light-emitting diodes (LED) via the LED driver. ESP32 will change the pulse width modulation (PWM) value on the LED driver according to the input from the user which is obtained through the cloud server. The $24 \mathrm{~V}$ and 1.2 A power supply is connected directly to the LED driver which is then distributed to a series of 24 Watt HPL LEDs.

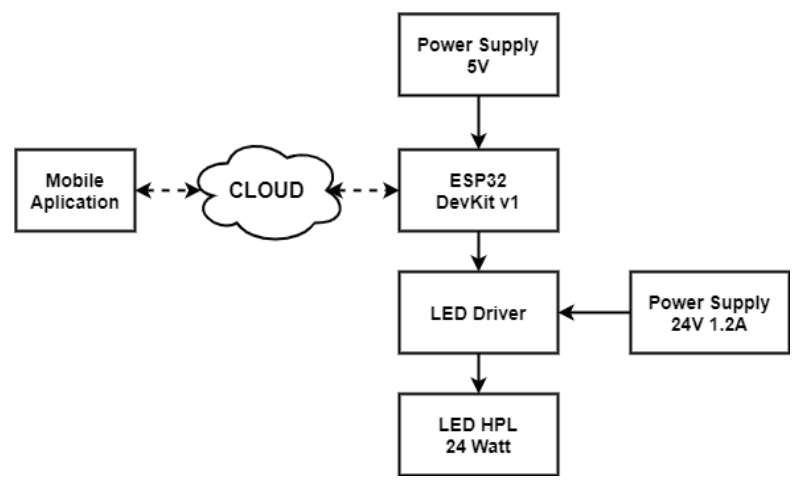

Figure 1. Block diagram of the controllable LED

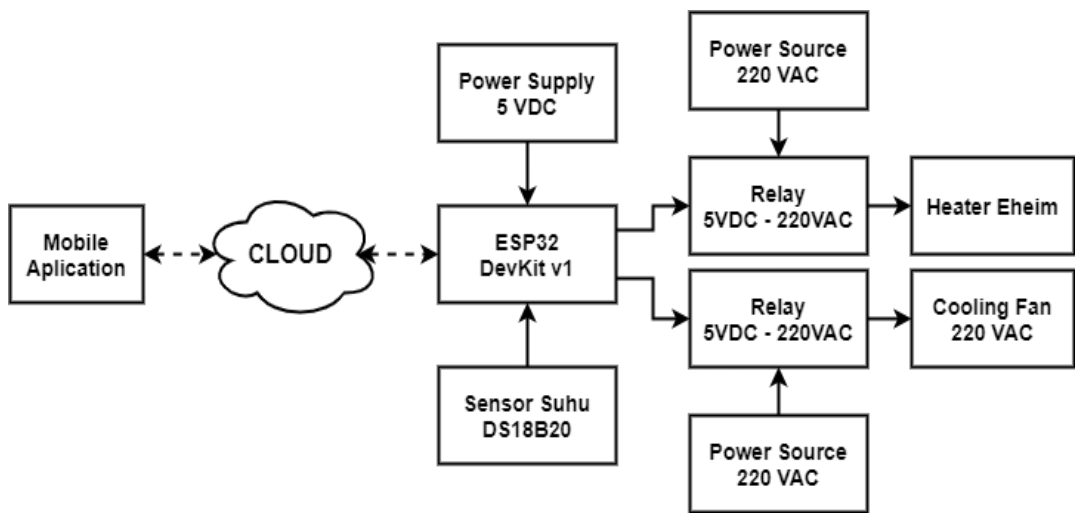

Figure 2. Block diagram of the temperature controller 
Based on the block diagram in Figure 2, the mobile application and ESP32 DevKit v1 are connected to each other via Cloud using the internet network. ESP32 DevKit v1 uses a DS18B20 temperature sensor to get temperature data. The $5 \mathrm{~V}$ power supply serves to provide voltage for the ESP32 DevKit v1 where the ESP32 functions to control the high and low temperature by using an Eheim Heater or 220 VAC cooling fan. If the temperature is too low, the ESP32 will turn on the Eheim Heater by providing an output signal to the $5 \mathrm{VDC}-220 \mathrm{VAC}$ relay connected to the heater. Meanwhile, if the temperature is too high, the ESP32 will turn on the cooling fan $220 \mathrm{VAC}$ by providing an output signal to the $5 \mathrm{VDC}-220 \mathrm{VAC}$ relay connected to this fan. The schematics diagram for the developed system is shown in Figures 3 and 4 while the developed android smartphone application is shown in Figure 5.

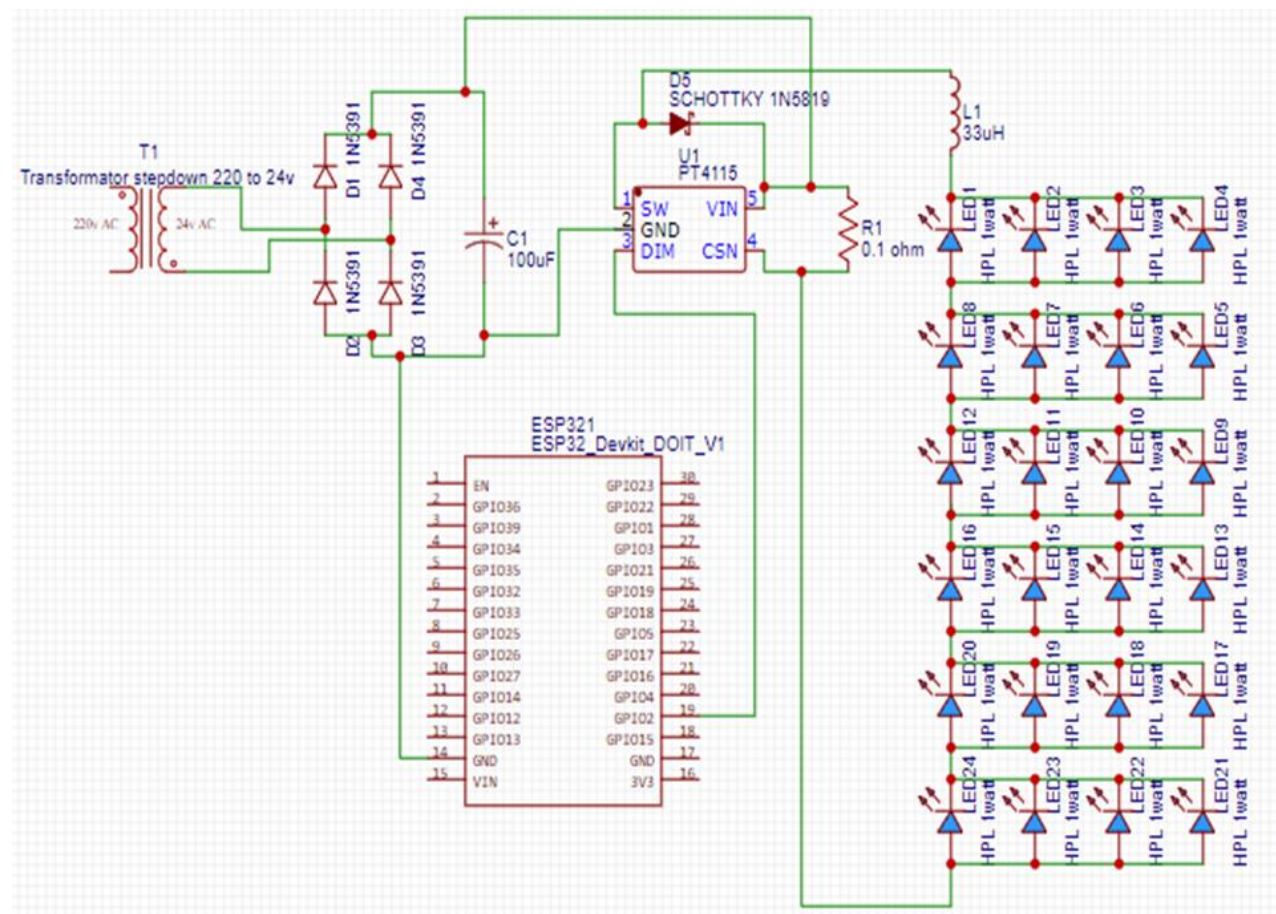

Figure 3. The schematics diagram of the controllable LED

Based on the Figure 3, it can be seen that the design of the controllable LED uses a $220 \mathrm{~V}$ to $24 \mathrm{~V}$ stepdown transformer, 4 1N5391 diodes as a current rectifier, a $100 \mathrm{uF}$ capacitor, PT4115 LED driver, 1N5819 schottky diode, $0.1 \mathrm{ohm}$ resistor, $33 \mathrm{uH}$ inductor, 36 HPL 1 watt LEDs, and 1 ESP32. Based on the Figure 4, it can be seen that the temperature controller design uses ESP32 components, a DS18B20 temperature sensor, a heater and two fans.

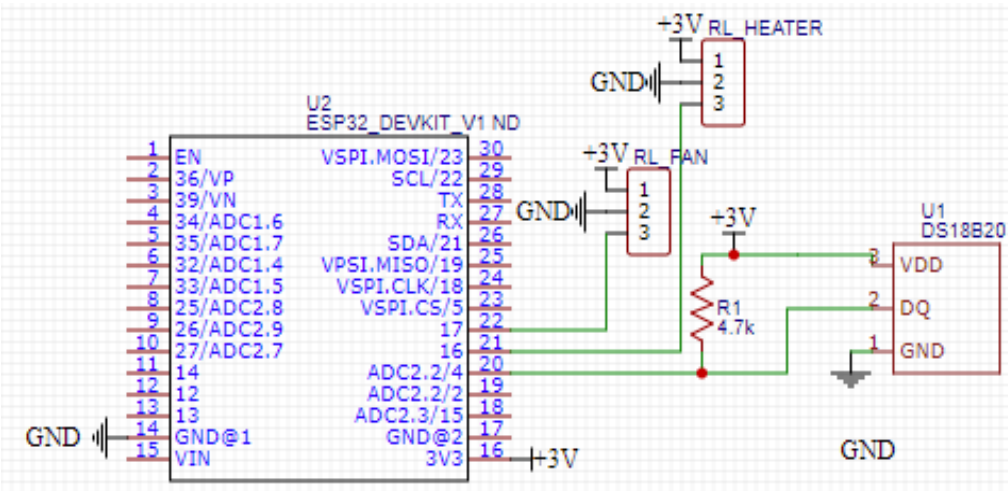

Figure 4. The schematics diagram of the temperature controller 

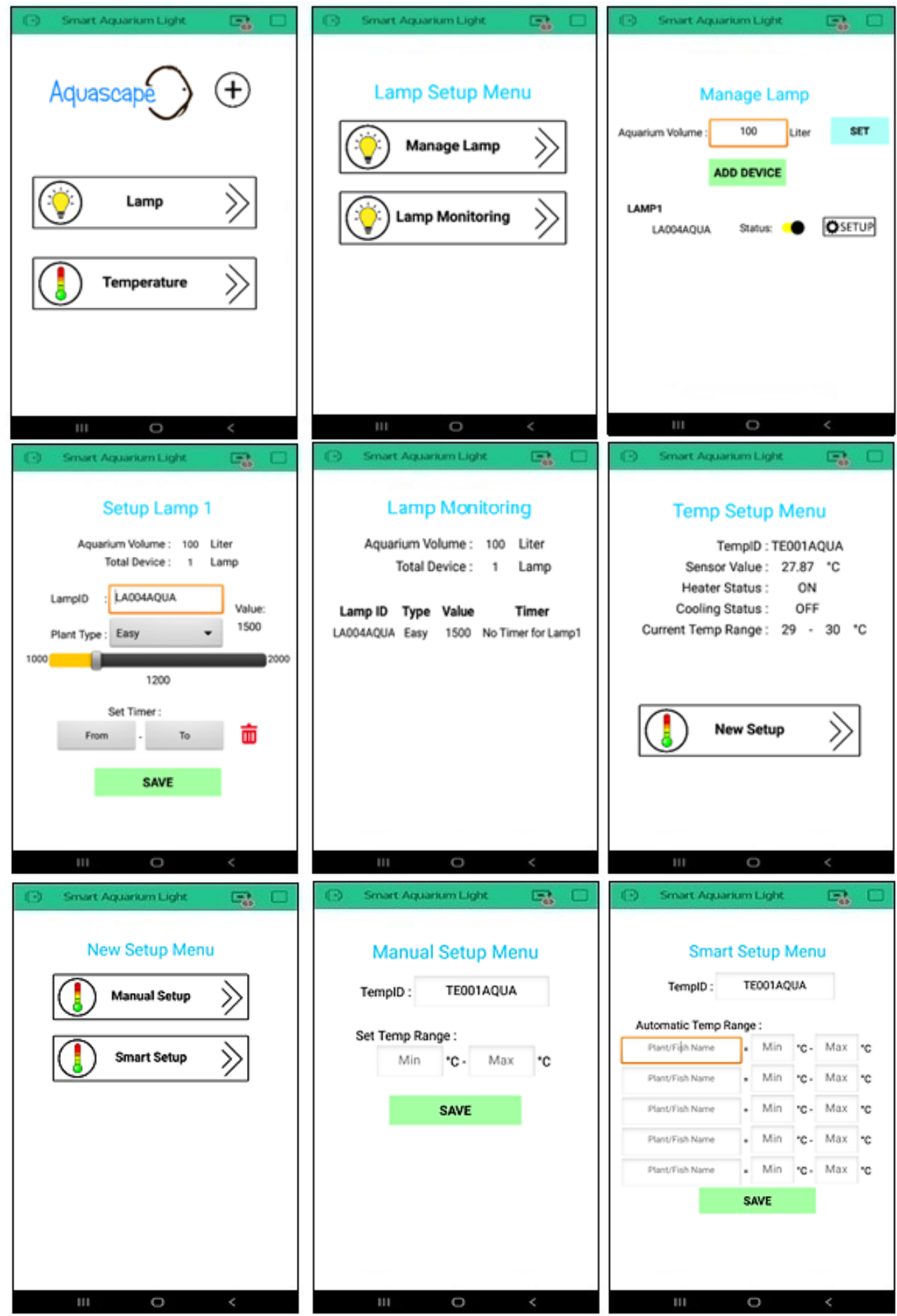

Figure 5. The developed android smartphone application

Based on the Figure 5, it can be explained the use of the mobile application sequentially from top left to bottom right as the following:

- The main menu is the page to enter the lamp setup or the temperature setup.

- The lamp setup menu is the page to enter the manage lamp or the lamp monitoring menu.

- The manage lamp menu is the page to make a new setup for the lamp. From this menu user can do several setups such as the setup for calculating the suggested LED output that is done by entering the value of aquarium volume, the setup for adding or reducing the number of LED used in the system, and the setup for individual LED by entering the setup lamp menu. 
- The setup lamp menu is the page to set individual output of LED according to the type of the plant and the working time of the LED.

- The lamp monitoring menu is the page to see the current setup of each LED.

- The temperature setup menu is the page to see the current setup of the temperature controller and also to monitor the condition of water temperature, heater, and fan. From this menu, user can make new setup by entering the new setup menu.

- The new setup menu is the page to enter new setup by using manual setup or smart setup.

- The manual setup menu is the page to enter new temperature setup manually according to the user's need.

- The smart setup menu is the page to enter the new temperature setup by first building the database of the plant that is used in the aquarium plant.

\section{RESULTS AND DISCUSSION}

In this study, the first test was carried out to see the accuracy of the LED output. In this test, user input is compared to the LED output and the relationship between user input and LED output is mapped and can be shown in Figure 6. From the Figure 6, it can be seen that the average of LED output is close to the value inputted by the user. it also concluded that the LED device calibration was successful. To see the average error percentage of the output LED is shown in Table 1.

\section{LED Output Average}

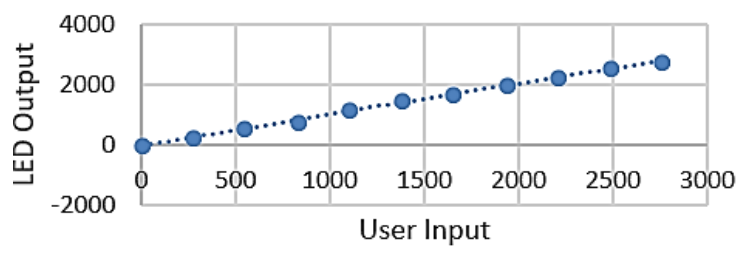

Figure 6. The accuracy of LED output

From Table 1 it can be seen that the average error is $4 \%$ where the highest error occurs at the LED output with a low lumens value. It can also be seen that the higher the lumens value, the smaller the error rate. This will later affect easy plants which require low lumens values. From the first test, it can be concluded that the accuracy of the LED device is around $96 \%$.

\begin{tabular}{|c|c|c|c|}
\hline User Input & LED Output & Error & Accuracy \\
\hline 276 & 225.63 & $9 \%$ & $91 \%$ \\
\hline 552 & 485.81 & $8 \%$ & $92 \%$ \\
\hline 828 & 775.20 & $5 \%$ & $95 \%$ \\
\hline 1104 & 1137.01 & $2 \%$ & $98 \%$ \\
\hline 1380 & 1448.48 & $4 \%$ & $96 \%$ \\
\hline 1656 & 1708.49 & $3 \%$ & $97 \%$ \\
\hline 1932 & 1980.29 & $2 \%$ & $98 \%$ \\
\hline 2208 & 2254.85 & $2 \%$ & $98 \%$ \\
\hline 2484 & 2544.77 & $2 \%$ & $98 \%$ \\
\hline 2760 & 2760 & $0 \%$ & $100 \%$ \\
\hline \multicolumn{2}{|c|}{ Average } & $4 \%$ & $96 \%$ \\
\hline
\end{tabular}

The second test was carried out to see the heater and fan response to the temperature changes. The system would turn on the heater if the temperature detected on the sensor is lower than the temperature of the user input and will turn on the fan if the temperature detected on the sensor is higher than the temperature of the user input. The heater will stop working if the water temperature is above the minimum value of the user input with a value difference of $30 \%$ from the difference between the maximum and minimum temperature values. Likewise, the fan will stop working if the water temperature is below the maximum value of user input with a value difference of $30 \%$ from the difference between the maximum and minimum temperature values. The result of the second test is shown in Table 2. 
Table 2. Heater and fan response to changes in temperature

\begin{tabular}{|c|c|c|c|c|}
\hline \multicolumn{2}{|c|}{ User Input } & \multirow[b]{2}{*}{ Sensor Value $\left({ }^{\circ} \mathrm{C}\right)$} & \multirow{2}{*}{ Heater Status } & \multirow{2}{*}{ Fan Status } \\
\hline Min. Temp $\left({ }^{\circ} \mathrm{C}\right)$ & Max. Temp $\left({ }^{\circ} \mathrm{C}\right)$ & & & \\
\hline 29 & 31 & 28.50 & ON & OFF \\
\hline 29 & 31 & 28.75 & ON & OFF \\
\hline 29 & 31 & 29.08 & ON & OFF \\
\hline 29 & 31 & 29.87 & OFF & OFF \\
\hline 29 & 31 & 30.85 & OFF & OFF \\
\hline 29 & 31 & 31.17 & OFF & ON \\
\hline 29 & 31 & 31.25 & OFF & ON \\
\hline 29 & 31 & 31.17 & OFF & ON \\
\hline 29 & 31 & 30.81 & OFF & ON \\
\hline 29 & 31 & 30.35 & OFF & OFF \\
\hline
\end{tabular}

From Table 2 it can be explained that the system developed can respond to temperature changes because the heater and fan can work according to the established rules. In Figure 7, you can see the system response when tested for nine hours at a temperature range of $29-31{ }^{\circ} \mathrm{C}$, from this figure it can be seen that at a certain time the temperature is out of the specified range with maximum difference $0.4{ }^{\circ} \mathrm{C}$ to the set value. This is due to the strong influence of room temperature and the time it takes for the device to return the temperature to the specified range.

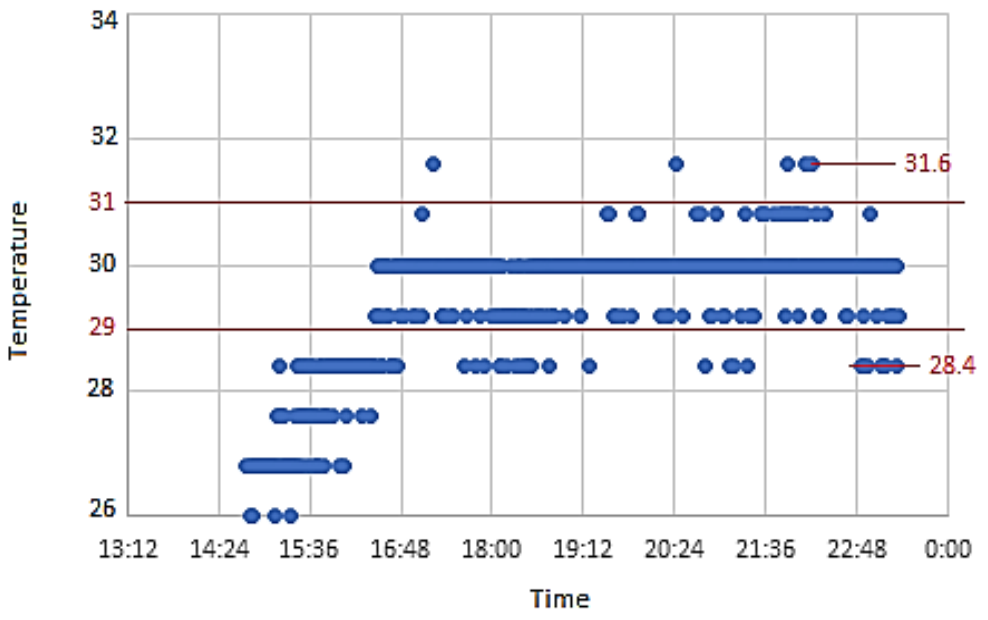

Figure 7. Response of the system due to changes in temperature

\section{CONCLUSION}

The system developed can produce accurate light intensity according to user input with an accuracy of $96 \%$. The system developed can also maintain the water temperature in accordance with the temperature required by the user with a maximum difference of $0.4{ }^{\circ} \mathrm{C}$ from the set value. The developed system is also $100 \%$ successful to turn on/off heater and fan cooler according to specified settings.

\section{REFERENCES}

[1] T. Tropica. "Light." Tropica.com. https://tropica.com/en/guide/make-your-aquarium-a-success/light/ (accessed Feb. 3, 2020).

[2] A. Aqueon. "Aquatic plant basics." aqueon.com. https://www.aqueon.com/resources/care-guides/aquatic-plant-basics (accessed Feb. 3, 2020).

[3] M. K. Anushree, and R. Krishna, "A smart farming system using arduino based technology," International Journal of Advance Research, Ideas and Innovations in Technology, vol. 4, no. 4, pp. 850-856, 2018.

[4] D. O. Shirsath, P. Kamble, R. Mane, A. Kolap, and R. S. More, "IoT based smart greenhouse automation using arduino," International Journal of Innovative Research in Computer Science and Technology (IJIRCST), vol. 5, no. 2, pp. 234-238, 2017, doi: 10.21276/ijircst.2017.5.2.4.

[5] J. Chandramohan, R. Nagarajan, K. Sateeshkumar, N. Ajithkumar, P. A. Gopinath, and S. Ranjithkumar, "Intelligent smart home automation and security system using arduino and Wi-Fi," International Journal of Engineering and Computer Science, vol. 6, no. 3, pp. 20694-20698, 2015, doi: 10.18535/ijecs/v6i3.53.

[6] R. Triantoro, R. Chandra, and D. P. Hutabarat, "Multifunctional aromatherapy humidifier based on ESP8266 microcontroller and controlled using Android smartphone," IOP Conference Series: Earth and Environmental Science, vol. 426, 2020, Art. no. 012152, doi: 10.1088/1755-1315/426/1/012152. 
[7] M. E. Syahputra and D. P. Hutabarat, "Eco friendly emergency alert system (EFEAS) based on microcontroller and android application," IOP Conference Series: Earth and Environmental Science, vol. 426, 2020, Art. no. 012160, doi: 1088/1755$1315 / 426 / 1 / 012160$

[8] D. P. Hutabarat, M S. Budijono, and R. Saleh, "Development of home security system using ESP8266 and android smartphone as the monitoring tool," IOP Conference Series: Earth and Environmental Science, vol. 195, 2018, Art. no. 012065, doi: 10.1088/1755-1315/195/1/012065

[9] T. Bhuvaneswari, J. Hossen, N. Asyiqinbt, A. Hamzah, P. Velrajkumar, and O. H. Jack, "Internet of things (IoT) based smart garbage monitoring system," Indonesian Journal of Electrical Engineering and Computer Science (IJEECS), vol. 20, no. 2, pp. 736-743, 2020, doi: 10.11591/ijeecs.v20.i2.pp736-743.

[10] M. W. Hariyanto, A. H. Hendrawan, and R. Ritzkal, "Monitoring the environmental temperature of the Arduino assistance engineering faculty using telegram," Journal of Robotics and Control, vol. 1, no. 3, pp. 96-101, 2020, doi: 10.18196/jrc.1321.

[11] A. Q. Bolaji, R. A. Kamaldeen, O. F. Samson, A. T. Abdullahi, and S. K. Abubakar, "A digitalized smart mobile home automation and security system via bluetoot/Wi-Fi using android platform," International Journal of Information and Communication Sciences, vol. 2, no. 6, pp. 93-99, 2017, doi: 10.11648/j.ijics.20170206.11.

[12] Y.I.N. Yuehong, "The Internet of things in healthcare: an overview," Journal of Industrial Information Integration, vol. 1, pp. 3-13, 2016.

[13] A. S. Parab and A. Joglekar, "Implementation of home security system using GSM module and microcontroller," International Journal of Computer Science and Information Technologies, vol. 6, no. 3, pp. 2950-2953, 2015

[14] O. Seosa and E. Promise, "GSM based intelligent home security for intrusion detection," International Journal of Engineering Intelligent Systems for Electrical Engineering and Communications, vol. 4, no. 10, pp. 595-605, 2014

[15] K. Smarsly, K. Georgieva, and M. König, "An internet-enabled wireless multi-sensor system for continuous monitoring of landslide processes," International Journal of Engineering and Technology, vol. 6, no. 6, pp. 520-529, 2014, doi: 10.7763/IJET.2014.V6.752.

[16] A. A. Beltran et al., "Arduino based food and water dispenser for pets with GSM technology control," International Journal of Scientific Engineering and Technology, vol. 4, no. 4, pp. 231-234, 2014, doi: 10.17950/ijset/v4s4/402.

[17] G. Saradha, "Simulation of earthquakes and tsunami through GSM network," 2011 International Conference on Emerging Trends in Electrical and Computer Technology, 2011, pp. 912-916, doi: 10.1109/ICETECT.2011.5760249.

[18] A. Sh. Dinkar and S. A. Shaikh, "Design and implementation of vehicle tracking system using GPS," Journal of Information Engineering and Applications, vol. 1, no. 3, pp. 1-6, 2011.

[19] S. Murugananham and P. R. Mukesh, "Real time web based vehicle tracking using GPS," Journal of World Academy of Science, Engineering and Technology, vol. 61, pp. 91-99, 2010.

[20] P. K. Harshadbhai, "Design of GPS and GSM based vehicle location and tracking system," International Journal of Science and Research, vol. 2, no. 1, pp. 165- 168, 2013

[21] D. P. Hutabarat, R. Susanto, A. Fauzi, and A. J. Wowor, "Designing a monitoring system to locate a child in a certain closed area using RFID sensor and android smartphone," Proceedings of the 5th International Conference on Communications and Broadband Networking, 2017, pp. 54-58, doi: 10.1145/3057109.3057115.

[22] P. Verma and J. S. Bhatia, "Design and development of GPS-GSM based tracking system with Google Map based monitoring," International Journal of Computer Science, Engineering and Applications (IJCSEA), vol. 3, no. 3, 2013, doi: 10.5121/ijcsea.2013.3304.

[23] S. G. Fernandez et al., "Smart soil monitoring and water conservation using irrigation on technology," Indonesian Journal of Electrical Engineering and Computer Science (IJEECS), vol. 19, no. 1, pp. 99-107, 2020, doi: 10.11591/ijeecs.v19.i1.pp99-107.

[24] A. R. F. Shafana and A. Aridharsan, "Android based automation and security system for smart homes," International Journal of Computer Science and Information Technology Research, vol. 5, no. 3, pp. 26-30, 2017.

[25] L. Kamelia, S. R. A. Noorhassan, M. Sanjaya, and W. S. E. Mulyana, "Door-automation system using bluetooth-based android for mobile phone," ARPN Journal of Engineering and Applied Sciences, vol. 9, no. 10, pp. 1759-1762, 2014

[26] S. Sankaranarayanan, A. T. Wan, and A. H. Pusa, "Smart home monitoring using android and wireless sensors," international Journal of Engineering and Manufacturing, vol. 4, no, 2, pp. 12-30, 2014, doi: 10.5815/ijem.2014.02.02.

[27] M. A. E. Mowad, A. Fathy, and A. Hafez, "Smart home automated control system using android application and microcontroller," International Journal of Scientific and Engineering Research, vol. 5, no. 5, pp. 935-939, 2014.

[28] P. Kumar, "Arduino based wireless intrusion detection using IR sensor and GSM," International Journal of Computer Science and Mobile Computing, vol. 2, no. 5, pp. 417-424, 2013. 